\title{
Agency and Sustainability in the Construction Industry
}

Dr Niamh Murtagh $^{1}$ and Dr Natalya Sergeeva ${ }^{1}$

${ }^{1}$ The Bartlett School of Construction and Project Management, University College London

\begin{abstract}
The construction industry is responsible for major environmental impact, particularly in terms of energy consumption, biodiversity and waste. As a sector, construction has unique characteristics including dependence on the temporary structure of the project for the delivery of its product, the built environment, and the requirement for joint working of many organisations, from micro to large. The lens of agency offers a valuable perspective with which to examine how individual professionals, projects and organisations can contribute to more sustainable outcomes. The chapter draws on the literature, primarily from psychology and construction research, to offer a review of relevant research from 2005. It explores conceptualisations of agency, and the role of agency in driving towards greater sustainability in construction. The findings note the dearth of research focusing directly on agency, and the evidence for mechanisms through which agency may exert influence, including professional and collective identities, professional and personal commitment to sustainability, narratives and framing, and the construction of knowledge. The chapter suggests questions for a future research agenda including examining success stories of sustainable construction through the lens of agency; exploring non-human agency such as materials, buildings and organisations; and the potential of altered discourses including visionary, future-oriented narratives.
\end{abstract}

Keywords: agency, built environment, construction, sustainability 


\section{Introduction}

A sustainable system has the ability to last indefinitely, drawing on its resources at a rate commensurate with their regeneration. Such a system does not consume irreplaceable assets on which its existence depends, use its reserves inefficiently or generate waste which poisons valuable resources. Globally there is agreement that human societies, with very rare exceptions, are not sustainable in their current form. Of the seven domains with quantified planetary boundaries within which human societies may be sustained, three have already exceeded the threshold of safe operating space: loss of biodiversity, climate change and the nitrogen/phosphorous cycle (Rockström et al., 2009). The construction industry has a significant impact on the first two of these three grand challenges. This chapter will explore the role of agency in driving environmental sustainability within construction.

The construction industry delivers the built environment, both buildings and infrastructure such as roads, sewers and power stations. Buildings consume an estimated $32 \%$ of total global final energy, and emit $19 \%$ of greenhouse gases and up to a third of fluorinated greenhouses gases which have significantly higher warming potential than carbon dioxide (Lucon et al., 2014). The emissions attributed to buildings are both direct, resulting from the buildings' operation (e.g. heating, cooling, lighting), and indirect, resulting from energy consumption for the activities within them (ibid.). Within the construction sector, embodied energy is a further concern, that is, the total energy consumed in the process of construction, including mining resources and manufacture and transport of products. Common construction materials - concrete, steel, aluminium, glass and many plastics - require very high levels of energy in their manufacture: one estimate puts steel and aluminium at $51 \%$ of embodied energy of buildings with concrete responsible for a further 17\% (Herczeg et al., 2014). Construction and demolition generates $25-33 \%$ of all solid waste in the EU (EU, 2019). 
Further the potential for the built environment to destroy or fragment ecosystems and habitats has been recognised for some time as a significant factor in biodiversity loss (Woodall \& Crowhurst, 2003). However, alongside its potential for damage to the natural world, the construction sector is a major source of employment globally, for example, employing over a quarter of a billion people and contributing 7\% of GDP in China (NBS, 2018). In addition, the products of construction provide societies with shelter, warmth and facilities ranging from healthcare to education, transport to housing, culture to industry. Radical transformation is needed to reduce the negative environmental impact while protecting social and economic benefits from the sector.

The construction industry is frequently characterised as unique (Dainty, Green, \& Bagilhole, 2007). Despite its economic importance, it is a fragmented sector. The majority of workers operate as sole tradespeople or in small businesses, with a small number of very large organisations (BEIS, 2020). Workers in the sector bring a very wide range of education and training backgrounds: from manual trades such as carpenter, electrician, plasterer, roofer, plumber and bricklayer, to professions requiring university degrees and professional accreditation such as architect, engineer (structural, mechanical, electrical, building services), planner, building control, quantity surveyor, land surveyor, project manager, and more. Construction work, whether of a small building or development of entire urban blocks or areas, is conducted as projects. Projects are defined as temporary endeavours that have specific goals, which teams of professionals work together to achieve (Turner \& Muller, 2003), and most projects are unique (Green, 2006). While large organisations in construction bring together many of the 'white-collar' roles, and typically hold the contract with the client, the work itself is sub-contracted through layers of contractors (builder organisations), who sub-contract in turn to specialist sub-contractors, who also sub-contract to smaller firms and 
individual tradespeople. Thus multiple organisations, from sole traders to global corporations, can be involved (see Fig. 1). To examine the role of agency in driving sustainability in construction, then, it is necessary to consider individuals, projects and organisations.

\section{INSERT FIGURE 1 HERE}

The concept of sustainability has been both over- and under-defined (Johnston, Everard, Santillo, \& Robert, 2007). Sustainable construction can be defined with reference to its product, the built environment, and has been succinctly described as "the creation and operation of a healthy built environment based on ecological principles and resource efficiency" (Kibert, 1994). Many assessment schemes exist globally to evaluate the levels of sustainability of buildings and other construction. The most widely used are LEED (Leadership in Energy and Environmental Design) from the US and BREEAM (Building Research Establishment Environmental Assessment Method) from the UK. BREEAM, for example, has ten categories of assessment including: energy, materials, waste, water, and health and well-being. Clearly, the primary focus is on minimising environmental impact. A sustainable construction industry will deliver buildings and infrastructure that are energyefficient and use renewable energy sources, are constructed from materials with a low carbon footprint in their production, minimise waste and water use, and provide facilities that support the health and well-being of their occupants and users.

Why is agency relevant to sustainable construction? Agency, in brief, refers to the capacity of the individual as an agent, that is, as an entity capable of enacting behaviour or making things happen. In the contexts of individual work, of projects and of organisations, individuals have the capability to make decisions, to choose how to work, and to elect to change or not how they work. Although the structure of the contexts will limit the extent of their agency, social 
structures do not determine how individuals will act. Having briefly outlined the unique challenges of the construction industry and the many aspects of sustainability that must be addressed, it is clear that transformation is challenging. While structural factors such as economic pressures and contractual arrangements are important, our contention is that the agency of the actor in construction is a critical component for change. It is the individuals in the industry who will make the decisions and who will elect (or not) to change what they do. This chapter therefore examines the question: What is the role of agency in achieving transformation of the construction industry to delivering a sustainable built environment?

It does so through a review of the literature on agency and sustainability in construction. The review is an expert, rather than systematic, review. We began with systematic searches but rapidly concluded that the keyword of 'agency' was not useful in surfacing work of relevance to the research question here, more often referring to 'government agency' and similar concepts. We discussed our understandings of the concept, drawing from our disciplines of psychology and construction management research, and went back to the literature to look for contemporary papers which spoke to individual action, decision-making or influence, in empirical or theoretical work on construction, on projects and in organisational contexts. No restriction was placed on source journals and, with the exception of one paper from 1998, the papers of interest were published between 2005 and 2020. The selection of papers is likely to be subjective but we believe the collection offers a comprehensive insight into how agency is conceptualised and investigated in scholarly work that is relevant to sustainable construction. The selected papers offered the basis for critical comment on the literature to date, pointers towards practical application and recommendations for future research. 
The chapter is structured as follows: after an introduction to theoretical treatments of agency to establish conceptual understanding, we look at individual agency in the context of construction, first how it is treated in general and then looking at work which has addressed its role in sustainable construction. We then move on to agency within construction projects, and lastly to papers examining agency within organisations in construction. In the final section, we summarise the insights from the papers and propose a list of recommendations for future research.

\section{Theoretical framings of agency}

In order to examine agency and sustainability in construction in the literature, it is necessary to set out theoretical understanding of what agency means. Sociology and psychology have addressed this question in different ways.

Structure and agency, and the relationship between them, can be seen as a central problem of sociological theory. To what extent do societal institutions versus individually selected actions determine outcomes? While Giddens' (1984) notion of structuration saw agency and structure as essentially conjoined, Archer (2003), in contrast, describes structure and agency from an ontological perspective as different strata of reality which are not reducible. Developing Bhaskar's (1998) argument that social agency mediates social institutions, Archer (2003) argues that the individual's reflexivity gives rise to inner dialogues. These internal conversations allow the individual to choose a position, and to act in accordance with that position, in response to external constraints. Thus it is this process originating in personal reflexivity which mediates the influence of social structures. The enactment of agency results in either structure reproduction or structure transformation, the morphogenetic cycle (Archer, 1995). 
While sociological perspectives have debated structure and agency, the notion of agency is implicit in the behavioural paradigms of the psychological perspective. This perspective therefore arguably has more to contribute to the topic of agency and it is on psychological framings that we will now focus. The individual is typically the unit of analysis within psychological theory and research, either solely or within a social context, and is conceptualised as bounded, conscious, active, competent and goal-oriented, to a lesser or greater extent depending on the subfield and research question. While there are subfields within psychology which challenge the conscious nature of human behaviour (in particular, the classic Freudian psychodynamic approach), most scholars in psychology envisage people to be "active, inquisitive, curious and playful creatures, displaying a ubiquitous readiness to learn and explore" (Ryan \& Deci, 2000). Thus much psychological-informed research takes as given the agentic nature of the person.

A number of theoretical frameworks have been developed within this paradigm to account for sustainable or pro-environmental behaviour. An early approach, developed to explain altruistic behaviour and subsequently widely applied to sustainable behaviour, was the Norm Activation Model (NAM; Schwartz, 1977). The NAM postulates that pro-environmental behaviour is triggered from personal norms, that is, feelings of moral obligation to undertake or abstain from particular actions. Personal norms in turn are influenced by problem awareness and ascription of responsibility. NAM proposes that people must first be aware of the consequences of their actions and take personal responsibility for negative outcomes in order to feel a sense of moral obligation to act. The model was subsequently extended to include values and ecological worldview as factors contributing to awareness of consequences in the Values-Beliefs-Norms (VBN) theory of environmentalism (Stern, Dietz, 
Abel, Guagnano, \& Kalof, 1999). More generally, Stern (2000) summarised four classes of variable which can have a causal influence on intention to act sustainably: attitudes (including general beliefs about the natural world, and norms and beliefs about specific actions), capabilities (including knowledge, skills and financial resources), context (including regulation, financial incentives and social norms) and habit (automatic actions). While attitudes, capabilities and habit may be viewed as attributes of the individual, contextual factors are external and not under the control of the individual, referring back to societal institutions. A more recent theory which integrates previous work, the Comprehensive Action Determination Model (CADM; Klöckner and Blöbaum 2010), includes the concept of perceived behavioural control. This important factor, originating in the Theory of Planned Behaviour (TPB: Ajzen \& Fishbein, 1977), emphasises that it is the individual's perception of control that is important. This is a critical insight from psychological theory - it is the individual's interpretation of societal constraints that influences their response, that is, structures do not directly determine outcomes.

All of the theories described have robust evidence supporting the role of multiple factors which may have a causal influence on sustainable behaviour. However, although all assume an agentic individual, they imply a somewhat passive one, at least in part at the mercy of behavioural determinants. In contrast, goal framing theory (Lindenberg \& Steg, 2007) proposes that people are goal-oriented and actively pursue overarching goals. These may be normative goals, with the aim of conforming to expected social norms; gain goals, with the aim to increasing one's resources; or hedonic goals, with the aim of increasing one's current well-being. Different goals may be triggered by the context, and behaviour is likely to consistent with the most strongly activated goal. The most strongly activated goal is termed the 'goal frame' as it frames the situation and guides what the individual will pay attention to, 
what knowledge they will access and what alternative they will consider (Kruglanski \& Kopetz, 2009). For sustainable behaviour, the goal frame should be greater sustainability, and policy, education and other means can be used to activate this goal in a construction context. In summary, psychological theories of environmental behaviour consider the individual as agentic and goal-oriented but not as free-willed and without constraints. Sustainable behaviour is driven and guided by external and internal factors, and an individual's decision making will be influenced both by their context and by how they think about the world, human and natural.

\section{Individual Agency}

Individual agency in the construction literature

Turning now to the domain of construction, we begin with individual agency in general in the construction literature before moving on to individual agency and sustainable construction. . We review papers which speak to the concept of agency at an individual level in order to set the context of how agency has been treated conceptually in construction research.

In an early application of structuration theory to address change in construction, change was recognised as a social process which includes adjustments to power, relationships and identities (Bresnen, Goussevskaia, \& Swan, 2005). Noting the common problems of construction including complexity of organisation, multiplicity of professions and value systems, and the consequent challenges for learning, Bresnen and colleagues argued that structuration theory enabled a focus on both social, cultural and spatial contexts and individual behaviour. Interestingly, they concluded from examination of two case studies that individual action may lead to learning, and therefore change, more effectively than organisational change campaigns. This finding positions agency as critical to transitions in 
construction. A more recent application of structuration theory was that of Tembo-Silungwe and Khatleli (2018) who used this theoretical framework to examine risk allocation in construction in Zambia. They defined social structure as comprising rules and resources, and argued that knowledge of rules can facilitate action to change them. However, in the empirical domain they studied, they found relatively little creativity in acting to modify existing rules and they noted that greater agency was required to achieve change.

The call from Bresnen and colleagues (2005) for better theoretical framing which should include sensitivity to complexity, social embeddedness and the dialectic between individuals and their setting was echoed by Harty (2008). Harty's paper aimed to show the insights to be gained through applying sociological theories to construction. He discussed Weberian notions of people's actions creating society and observed the importance of a theoretical focus on power. The centrality of power in shaping discourse, and therefore, how problems are understood and what solutions may be considered, was argued in Ness' (2010) sharply insightful critical analysis of the Respect for People campaign in construction. Ness compared the Kantian position of people as actors capable of moral agency with current positioning of people as assets within an accountancy discourse that is, she argues, almost universal in construction. She noted "the primacy of profitability is completely taken for granted" (p. 485) in the sector and that such discursive patterns constrain how change can happen. Her argument implies that prevalent discourses will limit possible avenues of transition to sustainability but that emphasising the moral agency of individuals can help to argue for different understandings and more possibilities for change, a position which aligns with the NAM theory discussed earlier. 
In their paper offering a revised research agenda for construction, Brown and Phua (2011) expounded the importance of identities. While the paper positioned agency as an unquestioned assumption ("People are reflexive, and make choices and decisions continuously which determine work outcomes" p. 84), the discussion also acknowledged the potentially constraining influence of discourses. The discussion linked identities, and professional identities in particular, to knowledge, competence and ethics: there are clear implications for identities - and thus individual agency - as a factor in more sustainable action in the sector.

Taking a social constructionist perspective in which strategic action fields (meso-level domains incorporating clusters of actors and contexts) emerge from the behaviours of individuals and groups as actors, Fellows and Liu (2017) argued that sense-making is a prerequisite for action. Although agency was not directly addressed, the centrality of sensemaking by the individual within their context argues in favour of outcomes driven by individual and group decision-making. This perspective was elaborated in Çidik and Boyd (2020) who examined multidisciplinary design teams. They showed the reciprocal generation of individual and group sense-making - the individual requires a sense of purposefulness to motivate individual action and this both contributes to and derives from the group sense of purposefulness. However, the sense-making is not context and value free: more powerful individuals and groups, including those with institutional authority or valued knowledge, can play a more dominant role in 'sense-giving' and defining the situation.

Moving on from Çidik and Boyd's (2020) work which echoed aspects of goal-framing theory, the capacity to define a situation was considered by Rasmussen and colleagues (2017) in their paper on framing and institutional change. They argued that the framing of a policy 
crucially influences its acceptability although individuals remain free to interpret different meanings from what is presented. They examined the case of an attempt to introduce a benchmarking policy in Danish construction but point to its failure to establish a coherent motivational frame as contributing to its lack of success. This challenges rationalist approaches to policy making and institutional change. For sustainability transitions, it underlines the importance of framings while acknowledging also the space for agentic actors to accept or resist the initiative. Sense-making was further considered by Newton (2016) in a theoretical paper on knowledge and experience. Drawing on understanding of knowledge as comprising both declarative and tacit forms, Newton proposed that tacit knowledge emerges from professional practice. Professional enactment or experience is predicated on sensemaking which in turn requires agency. Thus agency is a core factor in professional experience and knowledge.

A final paper in this section is that of Kurokawa and colleagues (2017) who used Actor Network Theory (ANT) to critique simplistic views of the client in the construction literature. Harnessing Latour's (2005) proposals of actor-networks as heterogeneous networks of actants and devices which connect them, the theoretical approach serves as a reminder of a perspective in which agency does not reside in individuals: in ANT, agency is distributed throughout the network and may be influenced by non-human actants as well as human. This has implications for sustainability transitions, moving beyond the unitary individual as the site of agency.

This set of papers shows, first, how little work in construction research has addressed the concept of agency directly. The few that have noted the potential for moral agency as a motivation for change and that the agency of non-human actants should also be considered. 
Second, where theoretical perspectives have addressed agency implicitly, it is through the lenses of learning, professional practice, identities and sense-making. Lastly, the work points to the constraints on agency, including context, discourses, sense-giving by more powerful actors and policy framing.

Individual agency and sustainability in the construction literature

Having reviewed salient papers on agency in construction, which although without a focus on a transition to greater sustainability still offer valuable implications for such change, we now consider papers which specifically address the challenges of sustainable construction with a perspective incorporating agency. There was noticeably little research with this focus, and most was recent.

In an early contribution addressing the role of construction professionals, Janda and Parag (2013) took what they termed a 'middle out' approach in contrast to the prevalent top-down (policy) and bottom-up (market demand) perspectives. The paper represented an important contribution in its focus on professionals involved in energy efficient buildings. It offered a strong argument for the significance of middle-actors as often-overlooked agents of change. In Parag and Janda (2014), the authors developed their argument and emphasised the essential nature of agency and agents' capacity in transitions, although they appeared to conflate structural factors in their definitions of agency and capacity.

Taking a socio-materiality perspective in their study on domestic retrofit, Buser and Carlsson (2017), like Kurokawa et al. (2017), considered agency to be exercised by people and things. Where ANT pursues symmetry in treating humans and objects as equal-status actants, socio- 
materiality does not assume a symmetrical relationship. Nevertheless, material agency is recognised, that is, the capacity of objects to act in their own right. Such agency is exercised within human practices which give meaning to things but the authors noted that meanings are dynamic and open to change. Attributes of both people and material objects are not fixed and are mutually created. There are important implications for sustainable construction: the physical objects of the build process, from the site to the materials to a building being refurbished, should be considered as actors exerting influence. Equally however, that influence may be interpreted and re-interpreted differently by different people at different times. Socio-materiality draws from sociotechnical systems thinking, applied by Lowe and colleagues (2018) in a paper exploring case study methodology on building performance. They highlighted the complexity of construction processes and noted that agency, while essential, does not occur in a vacuum but is embedded within social practices.

Examining organisational change for sustainability with a focus on individual agency, Gluch and Bosch-Sijtsema (2016) applied the lens of institutional theory which positions institutional work as the actions of individuals and organisations which may disturb or reproduce existing, or generate new, institutions. Agency is seen as fundamental to institutional work and may be attributed to artefacts as well as people, echoing socio-material and ANT perspectives. Gluch and Bosch-Sijtsema investigated the work of environmental experts within construction organisations and concluded that too much effort on maintaining existing institutions (for example, monitoring and reporting) constrained the freedom needed to exercise agency to disrupt institutions and bring about significant change. Their argument positioned professionalisation as inseparable from institutionalisation and professionals were positioned as potentially influential agents of change. In this, they echoed the work of Foxell (2019) whose book on professionalism in construction described and then challenged 
professionals in construction to show leadership and responsibility in stewardship of the environment.

Research with architects has also related sustainable practices to professional identity but additionally to autonomous motivations such a personal commitment to the environment and high standards of quality (Murtagh, Roberts, \& Hind, 2016). Of particular note was the way some participants explicitly linked their interest in sustainable design to personal 'green identity' which transcended their identity as professionals. Developing their work in examining the role of urban planners, Murtagh, Odeleye and Maidment (2019) applied a critical realist perspective grounded in the work of Roy Bhaskar and Margaret Archer. Based on their empirical work, they proposed professional commitment to a better environment to be a generative mechanism for sustainable outcomes in construction, with enabling conditions including personal commitment, and not only professional but also organisational and team identities (for planners working in local authorities). Constraining conditions limiting the potential of the generative mechanism included weak legislation and stakeholder and political pressures. Thus professional agency can lead to more sustainable outcomes but structural factors such as poor policy and power may thwart it.

Providing a cautionary commentary, Hargreaves (2018) pointed out how UK policy has embedded assumptions of individualistic agency in initiatives on energy feedback in the home. He argued that such a reductionist approach is inadequate to achieve substantive change. Individuals act within social, cultural and historical contexts of systems and practices, which offer multiple and often competing feedback on behaviours. The systems and practices in turn are produced and revised by multiple agents, and attempts to influence single individuals without recognition of the multiplicity of agents is doomed to failure. 
Hargreaves' insights from research with a core group of actors, that is, building occupants, are valuable in positioning agency as always contextual and always multiply influenced.

In summary, the small number of papers which examine individual agency in sustainable construction includes both implicit and explicit consideration of the concept. Findings on the importance of middle-actors in energy efficiency and motivations of construction professionals rest on an unquestioned assumption of individual agency. More insightful are those studies applying theoretical perspectives in which agency is a focal concept. These describe the essential nature of agency in moving towards greater sustainability, and several hone in on professionalism and professional practice as a vehicle for exercising agency. However, there is agreement that agency is always embedded, that the meaning of sociallyconstructed constructs (including people and materials) can change, and that existing institutions such as poor policy and power relations can negate the influence of agency on sustainable outcomes. 


\section{Agency in project teams}

Having discussed the treatment of agency at an individual level, we now consider agency in project teams. In construction projects, team members are carefully selected to give the project the best prospect, and they may change throughout project life-cycle. According to Emirbayer and Mische (1998), agency is a temporally embedded process which is not only informed by the past (privileging routines and habits) but also oriented toward the future (projective ability to imagine future situations). The present, 'here and now', is seen as the agential moment of 'practical-evaluative' ability in which past habits and future projects may be contextualised. This view of agency is heavily influenced by Mead's (1932) argument that the present is a form of temporality; it is only in the present that we can observe and act as opposed to recalling or anticipating events. According to Mead (1932), the constant flux of events and their interpretation means that the past is open to reconstruction as it is constantly being re-interpreted in the light of novel experiences. These insights offer essential perspectives for the project which is in essence also temporally embedded, moving through stages from pre-initiation, to initiation and planning, to construction and finally to project execution. Emirbayer and Mische suggested that both during and between projects, agency may facilitate re-interpretation of past events and future goals.

Project managers play vital roles in integrating the sustainability agenda into the whole lifecycle of a projects from its initiation through to completion (Martens \& Carvalho, 2017; Silvius \& Schipper, 2014)(Martens and Carvalho, 2017; Silvius and Schipper 2014). Project managers strive to enhance collaboration among all project team members working towards a project mission. Projects themselves are vehicles of bringing different professionals together 
forming a collective identity (N. Sergeeva \& Zanello, 2018) and sustainability can become part of conversations and activities performed in projects (Shen, Hao, Wing-Yan, \& Yao, 2007; Valdes-Vasquez \& Klotz, 2013).

Bordass and Leaman (2013) have suggested a mechanism connecting a collective identity and action: they proposed a set of elements for a 'new professionalism' specifically orientated towards a more sustainable future. They highlighted the need for a shared vision across the construction professions, together with a greater use of post-occupancy evaluation in the form of 'Soft Landings' (i.e. a strategy adopted to ensure effective transition from construction to occupation). In addition, they raised questions in terms of who should be responsible for the resulting knowledge base. As they conclude:

“Today's tasks for building professionals include adding much more value with fewer natural and financial resources and not just minimizing negative consequences but helping to bring about regenerative change. Truly sustainable solutions require a broad view, responsiveness to context and attention to detail. Better outcomes also require innovation: Purposeful and painstaking improvement to processes, techniques and technologies, based on knowledge of what actually works in practice and what needs improving, or abandoning” (Bordass and Leaman, 2013: 5).

Their argument for a new professionalism encompassing sustainability is grounded on the assumption of agency - the capacity of construction professionals to reflect on their education and practice, and to seek out and effect change.

Focusing on the delivery of construction projects, Paolillo et al. (2016) applied the concept of emotional intelligence to explain integrated project delivery using lean tactics and highlighted 
people-centred innovation. They suggested that multilevel, multidisciplinary project teams deliver more successful projects through shared vision and values. They argued that "Shared values established through concerns for the environment, health, and safety of worker and stakeholders, and social responsibility can become the new norms for the industry as a whole. A common vernacular built on inclusivity and participation can allow new ideas to flood the industry with future trends and innovative solutions intended to facilitate a new way of living and working in the built environment." (Paolillo et al., 2016: 7).

Their emphasis on the role of individuals underlines the importance of creativity and thus human agency, with the suggestion that shared values and vision act as mechanisms for change. Their "common vernacular" relates to the arguments put forward by Rasmussen et al. (2017) on framing, and, particularly, those of Ness (2010) on discourse. The concept of shared values echoes the insights of Çidik and Boyd (2020) on co-constructed sense-making by individuals and groups, and is of relevance for sustainability goals.

Finally in this section, Patel and Green (2020) viewed buildings in terms of ongoing enactments of socio-material practices, directing attention to the construction professionals and the whole lifespan of a building. Taking into consideration context, material and human agency, they placed emphasis on the processes of sustaining the knowledge base of construction professionals throughout the life-cycle of the project from planning to operation and argued that construction professionals should be active participants in such knowledge conversations rather than passive recipients. Their stance is relevant to our interests here since a whole life cycle perspective is seen as essential in the facilitation of greater sustainability, and the active construction of relevant knowledge is predicated on agency. 
In sum, from the relatively sparse papers in the project literature which address agency, relevant themes include the temporal nature of projects and of meanings; the role of collective identities in project teams; the importance of shared values; professional reflexivity and professional knowledge. Agency can facilitate reinterpretation of past events and future goals, thus project managers can reframe and reshapes narratives around sustainability goals. Collective identities are, in part, founded on shared values and shared goals, indicating that shared values around sustainability are an essential factor in projects delivering more sustainable construction. Professional identity and agency necessitate active involvement in knowledge creation, and knowledge is a defining feature of a profession (Foxell, 2019) and a prerequisite for a more sustainable built environment. This again points to mechanisms through which agency in project teams can deliver a more sustainable built environment.

\section{Agency in organisations}

Beyond project teams in construction, organisations play a central role in driving towards sustainability. In project organising, different organisations (clients, contractors, consultants in engineering, architecture or environment, specialist subcontractors) and actors work together towards a shared mission. Bonham (2013) argued that government clients are key agents for leading and motivating change in the creation of a more sustainable built environment through the piloting of new professional practices. She emphasised communication and collaboration as essential characteristics of new professional roles within construction, and for the government client in particular. Clearly a number of new professional roles associated with sustainability in construction organisations have emerged and these include environmental managers, sustainability consultants, and corporate sustainability practitioners. Different mechanisms of communication, such as discourses, 
narratives and stories, influence changes to - and are influenced by changes in - new professional roles and practices in organisational contexts. Construction professionals and their stories of everyday experiences can show how a dominant narrative of sustainability is lived in practice, at work and outside work. Common discourses around zero-carbon, energy efficiency, building physics and green buildings are evident from communications materials produced and promoted by construction organisations. Thus narratives and discourses may constitute mechanisms through which agency is exerted within and between organisations, and transformation is achieved.

However research approaches to discourses and narratives may overlook the importance of agency or side-line agency altogether. Zhao et al. (2016) examined zero carbon building from the perspective of business model innovation. While they acknowledged that business models for zero carbon buildings are influenced by political, social and environmental conditions, the ways those who work on zero carbon buildings respond to the business models were omitted from their work. Sergeeva and Lindkvist (2019) further argued that the reduction of carbon emissions requires understanding of consequences at global, national, industry and firm levels and showed how these levels are connected to each other. They emphasised that the self-identities of professionals, their experiences and practices play an important role in influencing and responding to sustainability goals. Key industry players, including clients and suppliers, may practice innovation and can be willing to go beyond the expectations of policy. These firms may respond to the sustainability agenda at the industrial policy level by formalising their sustainability strategies; using innovative and sustainable technologies; creating new job roles with sustainability in their titles; and creating an environment and culture of sustainability and innovation that is built into their firms' and individuals' 
identities. In these ways, organisations may act as critical agents of change, and enable individual agency of their employees.

In another organisational study, Wright and colleagues (2012) identified and labelled multiple identity narratives which may be mobilised by sustainability managers faced with addressing the challenges of climate change. Examples include: 'green change agent', 'relational manager' and 'committed activist'. They argued that such identities are continuously constructed through interaction with others and uniquely situated in different contexts. Their argument therefore centred on individual agency at work in organisations, through identification and labelling of self-identities such as change agent. We would argue further that collective identities may be formed in the context of agency and sustainability in construction organisations(Jones, Vedula, Conger, \& Lenox, 2019). A collective sense of being and becoming 'green' and 'sustainable' creates a collective identity related to sustainability that drives and motivates individuals to make changes in their personal work practices and everyday life. Collectively, change towards a more sustainable future becomes increasingly feasible as collective agency enables and extends individual agency.

In sum, we can conclude that organisations change constantly, through continuous processes of interaction between organisational strategies and narratives, and individual agency and experiences. New professional roles relating to sustainability have emerged and communication is essential. This includes narratives and discourses. Organisations respond to goals within sustainability such as zero-carbon set at industry, national and international levels, and their internal narratives and discourses form part of the organisational response. This response can create a sense of a collective identity towards achieving a shared agenda of greater sustainability. 


\section{Conclusions and future research agenda}

Our short review of the literature on agency and sustainability in construction has revealed insights and gaps. What is clear is that the topic has had relatively cursory attention and has frequently been taken-for-granted rather than meriting a research focus. On this basis, we argue that the importance of agency is typically overlooked in favour of more concrete factors such as technology and policy. While a range of theories in previous work has been considered, including structuration theory, institutional theory, actor-network theory, sociomateriality and critical realism, much work has not been positioned within a theoretical framework.

The research which has examined agency directly has presented evidence of the criticality of agency and agents' capabilities for transformation. Agency however is not solely a characteristic of humans but can be considered as an attribute also of networks and material objects. This has important ramifications for construction, pointing to the role of site, building and materials as 'actors' in the progression to greater sustainability. This merits more academic research. Organisations too may act as critical agents of change.

In contrast to perspectives that assert the dominance of social institutions, such as some social practice or policy-focused approaches, the review here has pointed to insights which emphasise the mediating processes through which the individual perceives, experiences and responds to external events. Psychological theory has underlined the importance of the perception of contextual control in behavioural models and several papers described above recognised the role of individuals in sense-making, framing and interpreting. There is argument for individual action leading to learning and thus to change. Middle-actors and 
construction professionals more generally can be seen as agents of change and agency can lead to modification of structural rules. Personal commitment and values, and self-identity more generally, can contribute to and shape collective identities, including professional, organisational and team identities, which inform group or social sense-making and framing. The past can be reconstructed and can influence present agency, and so narratives and discourses may operate as processes for transformation.

In the context of construction projects, it is important to pay greater attention to the whole life-cycle from the point when a project is envisaged through feasibility, design, delivery and operation. Throughout a project life-cycle, changes are inevitable (e.g. timeframe, cost amendments, people joining and leaving) with different actors involved in the process. Such a view reinforces change as a social activity with many professions involved in projects (e.g. project managers, architects, specialist suppliers). This provides a basis for understanding the ways in which sustainability is conceptualised and enacted from the agency perspective. If the quest for sustainability is indeed to become an essential dominant narrative then it needs to become central to the identities of all those involved in projects, including building occupants. We emphasise that agency does not operate in a vacuum and agency is in constant tension with complex and multiple contextual constraints. Weak legislation, political pressures, maintaining existing structures, prevailing discourses and many other factors constrain the exercise of agency. A focus on agency should not lead to a reductionist, individualistic approach.

In order to build on the relatively small base of knowledge on agency and sustainability in construction, a number of topics and research questions for future work can be proposed. 'Success stories' should be examined, through the lenses of agency and structure, and this 
could illuminate the processes through which transformation has been accomplished. Organisational change would be of particular interest here - building on the suggestions above, how do organisations become agents for change towards sustainability? There is potential in investigating the role of materials and buildings as agents. How are particular materials or building forms interpreted as more or less sustainable, what implications does this carry, and what scope exists to re-interpret such meaning?

The materiality of the built environment in itself creates a story about value creation through the life-cycle from initiation to operation to demotion. Further research is recommended to explore the symbolic nature of materiality and the creation and re-creation of value over time. For example, there is work emerging on the temporal development of the symbolic nature of megaprojects (Van Marrewijk, 2017). Given the domination of the accounting discourse in construction, what other discourses could be used to challenge this? Research exploring the lived experiences of professionals who practice sustainability in their professional roles offer potential. Ethnographic and diary studies may be particularly valuable here. More multidisciplinary research and multilevel understanding of the individual and organisational responses to the global sustainability agenda are needed. For example, psychologically informed studies could provide complementary insights into organisational and project management studies on agency and sustainability.

Finally, recognising the recent publication of The Future We Choose (2020) by Christina Figueres, Executive Secretary of the UN Framework Convention on Climate Change 20102016, with Tom Rivett-Carnac, future visions - positive or negative - may exert strong influence. More research is needed on visionary and future-oriented narratives, constructed at different levels, which allow individuals, groups and organisations to connect in ways that emphasise, facilitate and extend their agency for a sustainable future built environment. 


\section{Reference list}

Ajzen, I., \& Fishbein, M. (1977). Attitude-behavior relations: Theoretical analysis and review of empirical research. Psychological Bulletin, 84(5), 888-918.

Archer, M. S. (1995). Realist social theory: the morphogenetic approach. Cambridge: Cambridge University Press.

Archer, M. S. (2003). Structure, agency and the internal conversation. Cambridge: Cambridge University Press.

BEIS. (2020). Business population estimates for the UK and regions 2019. Retrieved from https://www.gov.uk/government/statistics/business-population-estimates-2019

Bhaskar, R., \& Lawson, T. (1998). Introduction: Basic texts and developments. In M. Archer, R. Bhaskar, A. Collier, T. Lawson, \& A. Norrie (Eds.), Critical realism: Essential readings (pp. 1-12). London: Routledge.

Bonham, M. B. (2013). Leading by example: new professionalism and the government client. Building research and information, 41(1), 77-94.

Bordass, B., \& Leaman, A. (2013). A new professionalism: remedy or fantasy? Building research and information, 41(1), 1-7.

Bresnen, M., Goussevskaia, A., \& Swan, J. (2005). Implementing change in construction project organizations: Exploring the interplay between structure and agency. Building research and information, 33(6), 547-560.

Brown, A. D., \& Phua, F. T. T. (2011). Subjectively construed identities and discourse: towards a research agenda for construction management. Construction Management and Economics, 29(1), 83-95. 
Buser, M., \& Carlsson, V. (2017). What you see is not what you get: single-family house renovation and energy retrofit seen through the lens of sociomateriality. Construction Management and Economics, 35(5), 276-287.

Çıdık, M. S., \& Boyd, D. (2020). "Shared sense of purposefulness": a new concept to understand the practice of coordinating design in construction. Construction Management and Economics, 38(1), 18-31.

Dainty, A., Green, S., \& Bagilhole, B. (2007). People and culture in construction: A reader. London: Taylor and Francis.

Emirbayer, M., \& Mische, A. (1998). What is agency? The American journal of sociology, 103(4), 962-1023.

EU. (2019, 2019). Construction and demolition waste (CDW). Retrieved from $\underline{\text { http://bit.ly/1ERulE1 }}$

Fellows, R., \& Liu, A. M. M. (2017). 'What does this mean'? Sensemaking in the strategic action field of construction. Construction Management and Economics, 35(8-9), 578596.

Figueres, C., \& Rivett-Carnac, T. (2020). The future we choose: surviving the climate crisis. London: Manilla Press.

Foxell, S. (2019). Professionalism for the Built Environment. Abingdon, Oxford: Earthscan/Routledge.

Giddens, A. (1984). The constitution of society. Oxford: Blackwell Publications.

Gluch, P., \& Bosch-Sijtsema, P. (2016). Conceptualizing environmental expertise through institutional work. Construction management and economics, 34(7), 522-535.

Green, S. (2006). The management of projects in the construction industry: context, discourse and self-identity. In D. Hodgson \& S. Cicmil (Eds.), Making projects critical (pp. 232-251). Basingstoke, Hants.: Palgrave Macmillan. 
Hargreaves, T. (2018). Beyond energy feedback. Building research and information, 46(3), $332-342$.

Harty, C. (2008). Sociology and construction management research: issues, approaches and implications. Paper presented at the 24th Annual ARCOM Conference, Cardiff, UK.

Herczeg, M., McKinnon, D., Milios, L., Bakas, I., Klaassens, E., Svatikova, K., \& Widerberg, O. (2014). Resource efficiency in the building sector. Rotterdam: ECORYS Nederland BV.

Janda, K. B., \& Parag, Y. (2013). A middle-out approach for improving energy performance in buildings. Building Research and Information, 41(1), 39-50.

Johnston, P., Everard, M., Santillo, D., \& Robert, K.-H. (2007). Reclaiming the definition of sustainability. Enviromental Science Pollution Research, 14(1), 60-66.

Jones, J., Vedula, S., Conger, M., \& Lenox, M. (2019). The collective construction of green building: industry transition toward environmentally beneficial practices. Acadamy of management perspectives, 33(4), 425-449.

Kibert, C. J. (1994, 6-9 November). The next generation of sustainable construction. Paper presented at the Proceedings of the First International Conference on Sustainable Construction, Tampa, Florida.

Klockner, C., \& Blobaum, A. (2010). A comprehensive action determination model: toward a broader understanding of ecological behaviour using the example of travel mode choice. Journal of Environmental Psychology, 30, 574-586.

Kruglanski, A. W., \& Kopetz, C. (2009). The role of goals in human self-regulation. In E. Morsella, J. A. Bargh, \& P. M. Gollwitzer (Eds.), Oxford handbook of human action (pp. 350-367). Oxford: Oxford University Press. 
Kurokawa, M., Schweber, L., \& Hughes, W. (2017). Client engagement and building design: the view from actor-network theory. Building research and information, 45(8), 910925.

Latour, B. (2005). Reassembling the social: An introduction to actor-network theory. Oxford: Oxford University Press.

Lindenberg, S., \& Steg, L. (2007). Normative, Gain and Hedonic Goal Frames Guiding Environmental Behavior. Journal of Social Issues, 63(1), 117-137.

Lowe, R., Chui, L. F., \& Oreszczyn, T. (2018). Socio-technical case study method in building performance evaluation. Building research and information, 46(5), 469-484.

Lucon, O., Urge-Vorsatz, A., Zain Ahmed, H., Akbari, P., Bertoldi, L. F., \& al., e. (2014). Buildings. In Climate Change 2014: Mitigation of Climate Change. Contribution of Working Group III to the Fifth Assessment Report of the IPCC. Cambridge: IPCC.

Martens, M. L., \& Carvalho, M. M. (2017). Key factors of sustainability in project management context: a survey exploring the project manager's perspective. International journal of project management, 35(6), 1084-1102.

Mead, G. H. (1932). The philosophy of the present. London: Open Court Publishing. Murtagh, N., Odeleye, N. D., \& Maidment, C. (2019). Identities as enabling conditions of sustainability practices in urban planning: a critical realist exploration with planners in England. Urban planning, 4(4).

Murtagh, N., Roberts, A., \& Hind, R. (2016). The relationship between motivations of architectural designers and environmentally sustainable construction design. Construction management and economics, 34(1), 61-75.

NBS. (2018). Annual national accounts: Value-added by industries. Retrieved from http://data.stats.gov.cn/english/easyquery.htm?cn=C01. Access date 5.8.2020. 
Ness, K. (2010). The discourse of 'Respect for People' in UK construction. Construction Management and Economics, 28(5), 481-493.

Newton, S. (2016). The being of construction management. Construction management and economics, 34(7-8), 458-470.

Paolillo, W., Olson, B. V., \& Straub, E. (2016). People-centred innovation: enabling lean integrated project delivery and disrupting the construction industry for a more sustainable future. Journal of construction engineering, 3704289, 1-7.

Parag, Y., \& Janda, K. B. (2014). More than filler: Middle actors and socio-technical change in the energy sytem from the "middle-out2. Energy reseach and social science, 3, 102-112.

Patel, H., \& Green, S. D. (2020). Beyond the performance gap: reclaiming building appraisal through archival research. Building research and information, 48(5), 469-484.

Rasmussen, G. M. G., Jensen, P. L., \& Gottlieb, S. C. (2017). Frames, agency and institutional change: the case of benchmarking in Danish construction. Construction Management and Economics, 35(6), 305-323.

Rockström, J., \& al. (2009). A safe operating space for humanity. Nature, 461, 472-473.

Ryan, R. M., \& Deci, E. L. (2000). Self-determination theory and the facilitation of intrinsic motivation, social development and well-being. American Psychologist, 55(1), 68-78.

Schwartz, S. H. (1977). Normative influence on altruism. In L. Berkowitz (Ed.), Advances in experimental social psychology (Vol. 10, pp. 221-279). New York: Academic Press.

Sergeeva, N., \& Lindkvist, C. (2019). Narratives of innovation that address climate change agenda in the construction sector. In M. I. Havenvid, A. Linné, L. E. Bygballe, \& C. Harty (Eds.), The connectivity of innovation in the construction industry (pp. 288292). Oxford: Routledge. 
Sergeeva, N., \& Zanello, C. (2018). Championing and promoting innovation in UK megaprojects. International journal of project management, 36(8), 1068-1081.

Shen, L.-Y., Hao, J. L., Wing-Yan, V., \& Yao, H. (2007). A checklist for assessing sustainability performance of construction projects. Journal of civil engineering and management, 13(4), 273-281.

Silvius, A. J. G., \& Schipper, R. P. J. (2014). Sustainability in project management competencies: analyzing the competence gap of project managers. Journal of human resource and sustainability, 2(2), 40-58.

Stern, P. C. (2000). Toward a coherent theory of environmentally significant behavior. Journal of Social Issues, 56(3), 407-424.

Stern, P. C., Dietz, T., Abel, T., Guagnano, G. A., \& Kalof, L. (1999). A value-belief-norm theory of support for social movements: the case of environmentalism. Human Ecology Review, 6, 81-97.

Tembo-Silungwe, C. H., \& Khatleli, N. (2018). Risk allocation using structuration theory in the construction industryr. Journal of construction engineering and management, 04018021-1.

Turner, J. R., \& Muller, R. (2003). On the nature of the project as a temporary organization. International journal of project management, 21(1), 1-8.

Valdes-Vasquez, P., \& Klotz, L. E. (2013). Social sustainability considerations during planning and design: framework of processes for construction projects. Journal of construction engineering and management, 139(1), 80-89.

Van Marrewijk, A. H. (2017). The multivocality of symbols: a longitudinal study of symbolic dimensions of the high-speed train megaproject. Project management journal, 48(6), $1-13$. 
Woodall, R., \& Crowhurst, D. (2003). Biodiversity indicators for construction projects. Retrieved from London: CIRIA.

Wright, C., Nyberg, D., \& Grant, D. (2012). "Hippies on the third floor": climate change, narrative identity and the micro-politics of corporate environmentalism. Organization studies, 33(11), 1451-1475.

Zhao, X., Pan, W., \& Lu, W. (2016). Business model innovation for delivering zero carbon buildings. Sustainable cities and society, 27, 253-262. 
Figure 1

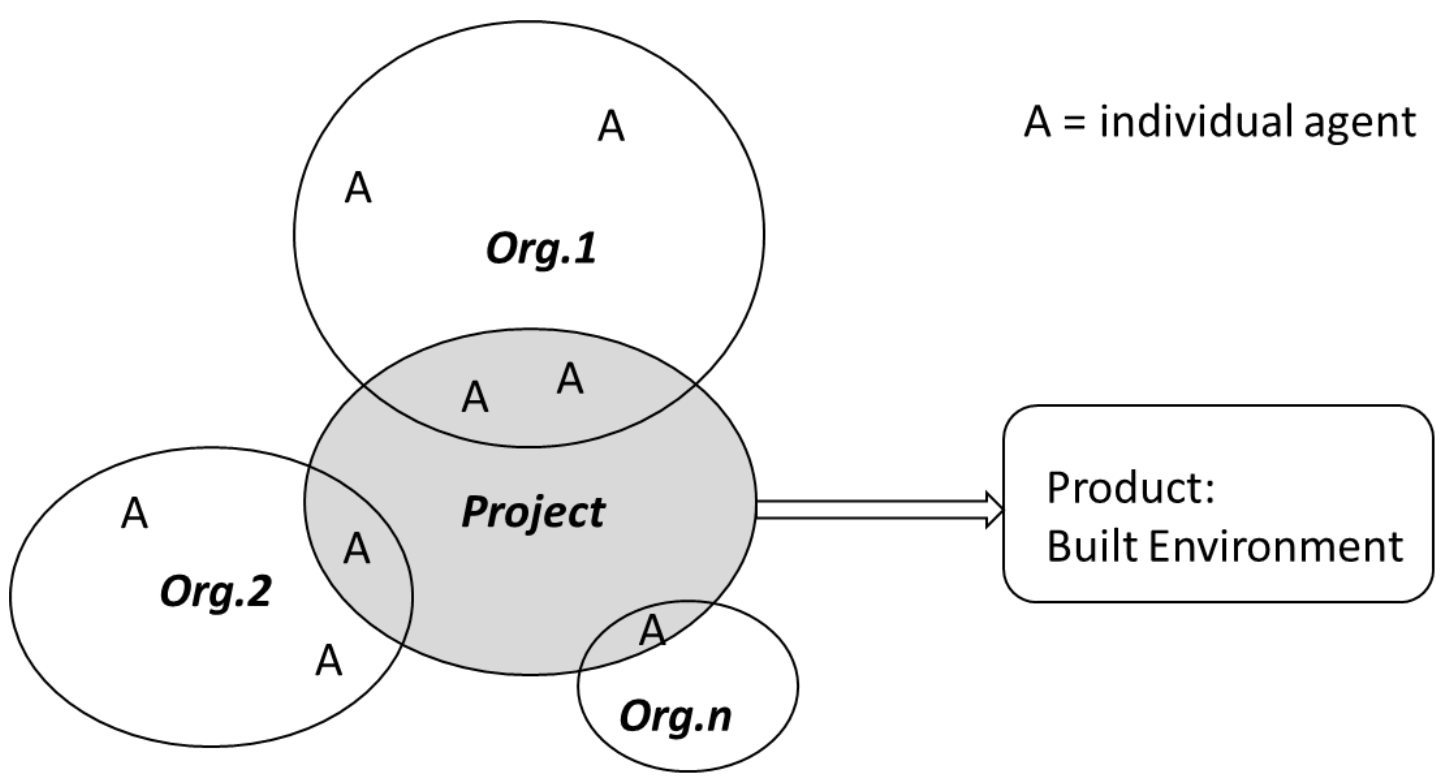

Fig. 1 Schematic of construction industry: agents, organisations, project and product 